\title{
Effect of Aldicarb Exposure on Cellular Immunity and Antioxidant Capacity in Kunming Mice
}

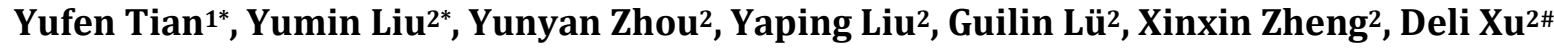 \\ ${ }^{1}$ Library, Qufu Normal University, Qufu, China \\ ${ }^{2}$ College of Life Sciences, Qufu Normal University, Qufu, China \\ Email: "xudl1975@163.com
}

Received 1 June 2015; accepted 11 July 2015; published 14 July 2015

Copyright (C) 2015 by authors and Scientific Research Publishing Inc.

This work is licensed under the Creative Commons Attribution International License (CC BY).

http://creativecommons.org/licenses/by/4.0/

\section{(c) (1) Open Access}

\begin{abstract}
Immune function and antioxidant defense play an important role in protecting animals against pathogens and in controlling oxidative stress, respectively. Aldicarb is of great concern for human health due to its toxic nature, its extensive usage and consequent pollution. The hypothesis that aldicarb exposure would suppress immune function and antioxidant capacity in Kunming mice was to be tested in the present study. Twenty-three adult male mice were randomly divided into the control $(n=11)$ and the aldicarb treated $(n=12)$ groups. Food and water were provided ad libtum for both groups, while the aldicarb treated mice drank aldicarb solution $(0.097 \mathrm{mg} / \mathrm{L})$ for 22 days. Cellular immunity assessed by phytohaemagglutinin (PHA) response did not differ between the control and the aldicarb treated groups. Similarly, white blood cells were not influenced by aldicarb treatment. Moreover, aldicarb exposure had not significant effect on body mass, all organ masses detected. However, aldicarb treatment suppressed total antioxidant capacity in liver but not in kidneys. In summary, aldicarb treatment did not affect immune function, but suppressed liver antioxidant capacity in Kunming mice.
\end{abstract}

\section{Keywords}

Aldicarb, Antioxidant Capacity, Kunming Mice, Phytohaemagglutinin Response

\section{Introduction}

Pesticides are hazardous pollutants which are abundant in soil, water, atmosphere and agricultural products. Be-

\footnotetext{
${ }^{*}$ Yufen Tian and Yumin Liu are co-first authors.

\#Corresponding author.
}

How to cite this paper: Tian, Y.F., Liu, Y.M., Zhou, Y.Y., Liu, Y.P., Lü, G.L., Zheng, X.X. and Xu, D.L. (2015) Effect of Aldicarb Exposure on Cellular Immunity and Antioxidant Capacity in Kunming Mice. Health, 7, 830-837. 
cause of their toxic nature, their extensive usage and consequent pollution, great environmental concerns have developed [1]. Aldicarb, an $N$-methyl carbamate pesticide, has many hazardous effects on humans and animals [2] [3]. In the past decades, control actions to ban or severely restrict aldicarb use have been achieved by Europe and other countries due to its toxic effects [4]. However, aldicarb is still used in agriculture in some developing countries including China [5] [6]. Thus, aldicarb is of great concern to human health because of its highly toxic effects.

The immune system defends human and animals against environmental pathogens, which plays an important role in maintaining health [7]. Some researchers have investigated the impact of aldicarb on immune function in human and animals. For example, Fiore et al. (1986) assessed the effects of chronic ingestion of low-level aldicarb-contaminated groundwater on the immune function of humans and found that abnormalities in T-cell subsets were related with the consumption of aldicarb-contaminated groundwater in women [8]. A follow-up study showed that changes in T-lymphocyte distribution were associated with ingestion of aldicarb-contaminated drinking water [9]. Moreover, Dean et al. (1990) found that aldicarb could inhibit the stimulatory activity of macrophages without affecting the T-cell responses in the syngeneic mixed lymphocyte reaction [10]. However, some other investigators got different results. For instance, aldicarb exposure had no significant effect on the ability of splenic natural killer cells, the percentages and absolute numbers of total T-cells, T-suppressor, Thelper, and B-cells in female B6C3F1 mice [11]. Many immunological parameters such as humoral, cellular and nonspecific immunity in mice were also not affected by chronic low level of aldicarb exposure [12]. Therefore, further researches are needed to clarify these discrepancies.

Phytohaemagglutinin (PHA) response has been used to assess mammalian cellular immunity, which belongs to adaptive immune system [14] [15]. Thymus is responsible for primary T cell development [16], and a larger spleen represents stronger immunity [17]. Total white blood cells (or leukocytes, WBC) are also used to evaluate the overall health [7].

Oxidative stress commonly defined as the imbalance between the production of reactive oxygen species (ROS) and the antioxidant capacity of the organism is deleterious to the structure and function of the cell and tissue, which is widely believed to be involved in many diseases [18] [19]. Therefore, antioxidant capacity prioritizing self-maintenance in animals plays a key role in maintaining their health [20].

In the present study, the hypothesis that aldicarb would have great influence on immune function and total antioxidant capacity in Kunming mice was tested. We expected that cellular immunity, thymus and spleen mass, white blood cells and total antioxidant capacity in liver and kidneys would be suppressed in aldicarb treated mice compared with the controls. The purpose of this study was to evaluated whether aldicarb exerted influences on immunity and antioxidant capacity in mice. We adopted the integrative research method including the morphological and biochemical method. We found that different parameters responded differently to adicarb exposure. These finding had implications for human health.

\section{Materials and Methods}

\subsection{Animals and Experimental Design}

All animal procedures were carried out according to the Institutional Animal Care and Use Committee of Qufu Normal University. Male Kunming mice (age: 2 months) used in this study were obtained from the Animal Breeding Center in Lukang Pharmaceutical Group Co., Ltd. of Shangdong province. The experiment was carried out from March 8 to April 4 in 2014. Mice were housed individually in plastic cages $(30 \mathrm{~cm} \times 15 \mathrm{~cm} \times 20 \mathrm{~cm}$ ) with sawdust as bedding. The raising conditions are semi-natural and the photoperiod was natural light. Animals had free access to water and food (Standard rat pellets chow, provided by Animal Breeding Center in Lukang Pharmaceutical Group Co., Ltd. of Shangdong province). After body mass stabilized, 23 mice were randomly divided into the control group $(n=11)$ and the aldicarb (manufactured by Shandong Huayang Technology Co., Ltd) treated group $(n=12)$ in which each mouse drank aldicarb solution $(0.097 \mathrm{mg} / \mathrm{L})$. The reason we chose this drank aldicarb solution concentration was that the content of aldicarb in one batch of gingers in Guangdong Jiangnan Fruit and Vegetable Wholesale Market was 0.097 mg/kg (http://baike.baidu.com/view/5560243.htm). The residue content of aldicarb in these gingers has exceeded that of the maximum residue content of aldicarb in vegetables $(0.03 \mathrm{mg} / \mathrm{kg})$ according to the "National food safety standard-Maximum residue limits for pesticides in food” (GB2763-2012) in China. The period of the experiment was 22 days. Day 0 and day n represented initial day and $n$ days of treatment, respectively. 


\subsection{Organ Index}

Organs were measured as described previously [21]. In brief, the visceral organs, including heart, thymus, lungs, liver, spleen, kidneys, testes, epididymis, seminal vesicals and the digestive organs with contents (i.e., stomach, small intestine, caecum and colon) were dissected and weighed ( $\pm 1 \mathrm{mg})$. The stomach, small intestine, caecum and colon were rinsed with saline to eliminate all the gut contents, before being weighed.

\subsection{White Blood Cells Assays}

At the end of the experiment, after collecting trunk blood, $20 \mu \mathrm{L}$ whole blood was diluted immediately in 0.38 $\mathrm{ml}$ solution containing $1.5 \%$ glacial acetic acid, $1 \%$ crystal violet (Sigma) and the leukocytes were counted in an improved Neubauer chamber using microscope. The total number of WBC was determined by counting all leucocytes in the four corner large-squares of the Neubauer chamber, and multiplying the raw data by $5 \times 10^{7}$ to obtain the final values $\left(10^{9}\right.$ cells/L) [22].

\subsection{Antioxidant Capacity Assays}

Liver and kidneys were homogenized using ice-cold $0.9 \% \mathrm{NaCl}$ solution. The homogenates were centrifuged at $3000 \mathrm{rpm}$ for $20 \mathrm{~min}$ and the supernatant was taken for the later assay. Total antioxidant capacity (T-AOC) and protein content in liver and kidney was measured using kits (Nanjing Jiancheng, Nanjing, China) according to the manufacturer's instructions. One unit of T-AOC was defined as the extent to which optical density is increased by 0.01 per milligram protein per minute.

\subsection{Cellular Immunity Assays}

PHA response indicative of cellular immunity was evaluated as described previously [15] [21]. Specifically, mice in the control and aldicarb treated groups on day 19 were caught, then we measured their footpad thickness of the left hind foot with a micrometer (Digimatic Indicator ID-C Mitutoyo Absolute cod. 547 - 301, Japan) to \pm $0.01 \mathrm{~mm}$. Immediately thereafter, mice in both groups were injected subcutaneously $0.1 \mathrm{mg}$ of PHA (PHA-P, Sigma L-8754) dissolved in $0.03 \mathrm{ml}$ of sterile saline (pH7.4) in the middle of the footpad. After $6 \mathrm{~h}, 12 \mathrm{~h}, 24 \mathrm{~h}$, $48 \mathrm{~h}$ and $72 \mathrm{~h}$ injection, we measured footpad thickness. The PHA response (i.e., cellular immunity) was calculated as the difference between pre- and post-injection measurements divided by initial footpad thickness (PHA response $=($ post PHA - pre PHA $) /$ pre PHA $)$. Six measures of footpad thickness were taken to obtain the value of each mouse [21].

\subsection{Statistical Analysis}

Data were analyzed using SPSS 13.0 software (SPSS Inc., Chicago, IL, USA). Prior to all statistical analyses, data were examined for normality and homogeneity of variance, using Kolmogorov-Smirnov and Levene tests, respectively. The ratio values such as PHA response were subjected to arcsine transformation. The differences of body mass between the control and aldicarb treated groups were analyzed by independent-samples t-test. Group differences in wet organ mass with body mass as the covariate were analyzed by General Linear Model multivariate analysis followed by Bonferroni post hoc tests. Group differences in other parameters (PHA response, WBC, T-AOC) were analyzed by independent-samples t-test. Results were expressed as mean $\pm \mathrm{SE}$, and $\mathrm{P}<0.05$ was considered to be statistically significant.

\section{Results}

\subsection{Body Mass}

On day 0 , body mass between the control and aldicarb treated groups was not different $(t=-0.185, \mathrm{df}=21, \mathrm{P}=$ $0.855)$. There was no difference of body mass between these two groups from day $1(\mathrm{t}=0.189$, $\mathrm{df}=21, \mathrm{P}=$ $0.852)$ to day $22(\mathrm{t}=-0.016, \mathrm{df}=21, \mathrm{P}=0.987)$ (Figure 1$)$.

\subsection{Organs}

Aldicarb treatment had no significant effect on the masses of heart, lungs, liver, kidneys, stomach, small intestine, caecum, colon, testes, epididymis, seminal vesicals and immune organs including thymus and spleen (Table 1). 


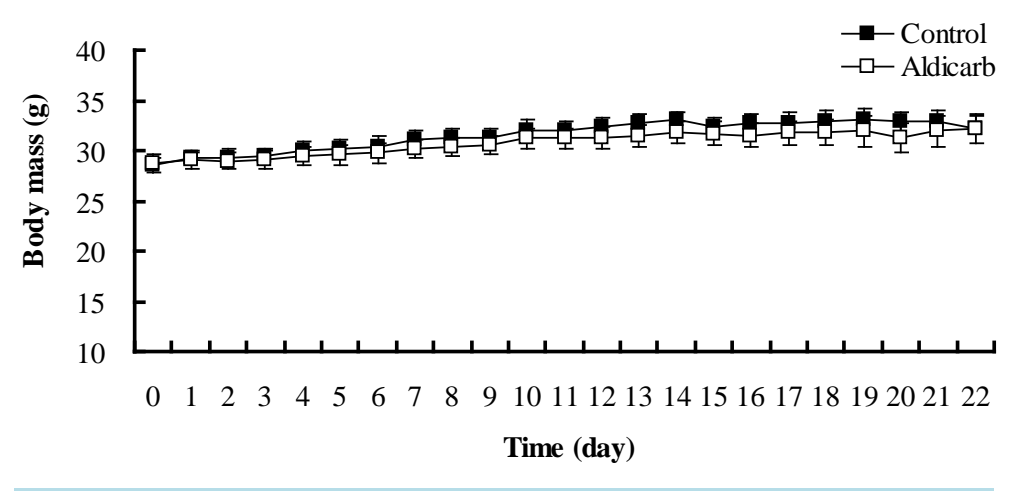

Figure 1. Changes of body mass in mice during aldicarb treatment. Values are means \pm SE. Body mass on day 0 between the control and aldicarb treated groups did not differ significantly.

Table 1. Effect of aldicrab on wet organ mass in Kunming mice.

\begin{tabular}{|c|c|c|c|c|}
\hline \multirow{2}{*}{$\begin{array}{l}\text { Parameters } \\
\text { Sample size }\end{array}$} & \multirow{2}{*}{$\begin{array}{c}\text { Control } \\
11\end{array}$} & \multirow{2}{*}{$\begin{array}{c}\text { Aldicarb } \\
12\end{array}$} & \multicolumn{2}{|c|}{ Statistical summary } \\
\hline & & & $\mathbf{F}_{1,20}$ & $\mathbf{P}$ \\
\hline Heart (g) & $0.161 \pm 0.007$ & $0.174 \pm 0.007$ & 1.685 & 0.209 \\
\hline Lungs (g) & $0.282 \pm 0.030$ & $0.315 \pm 0.029$ & 0.617 & 0.441 \\
\hline Thymus (g) & $0.057 \pm 0.005$ & $0.043 \pm 0.005$ & 3.985 & 0.060 \\
\hline Liver (g) & $1.664 \pm 0.059$ & $1.650 \pm 0.056$ & 0.031 & 0.863 \\
\hline Spleen (g) & $0.106 \pm 0.014$ & $0.128 \pm 0.013$ & 1.261 & 0.275 \\
\hline Kidneys (g) & $0.471 \pm 0.022$ & $0.484 \pm 0.021$ & 0.166 & 0.688 \\
\hline Stomach with contents (g) & $0.559 \pm 0.074$ & $0.555 \pm 0.071$ & 0.002 & 0.969 \\
\hline Stomach (g) & $0.232 \pm 0.015$ & $0.215 \pm 0.014$ & 0.754 & 0.396 \\
\hline Small intestine with contents (g) & $2.242 \pm 0.122$ & $2.201 \pm 0.117$ & 0.058 & 0.812 \\
\hline Small intestine (g) & $1.483 \pm 0.110$ & $1.315 \pm 0.106$ & 1.220 & 0.282 \\
\hline Small intestine length (cm) & $65.500 \pm 1.785$ & $64.333 \pm 1.709$ & 0.223 & 0.642 \\
\hline Caecum with contents (g) & $0.568 \pm 0.030$ & $0.613 \pm 0.029$ & 1.149 & 0.297 \\
\hline Caecum (g) & $0.200 \pm 0.018$ & $0.162 \pm 0.018$ & 2.224 & 0.151 \\
\hline Caecum length $(\mathrm{cm})$ & $3.455 \pm 0.135$ & $3.141 \pm 0.130$ & 2.799 & 0.110 \\
\hline Colon with contents (g) & $0.549 \pm 0.050$ & $0.613 \pm 0.048$ & 0.858 & 0.365 \\
\hline Colon (g) & $0.285 \pm 0.015$ & $0.317 \pm 0.014$ & 2.429 & 0.135 \\
\hline Colon length (cm) & $9.455 \pm 0.420$ & $9.799 \pm 0.402$ & 0.350 & 0.561 \\
\hline Total digestive tract (g) & $1.969 \pm 0.124$ & $1.794 \pm 0.119$ & 1.038 & 0.320 \\
\hline Total digestive tract length $(\mathrm{cm})$ & $78.410 \pm 1.910$ & $77.274 \pm 1.828$ & 0.185 & 0.672 \\
\hline Testes (g) & $0.219 \pm 0.012$ & $0.197 \pm 0.011$ & 1.866 & 0.187 \\
\hline Epididymis（g) & $0.051 \pm 0.010$ & $0.034 \pm 0.009$ & 1.580 & 0.223 \\
\hline Seminal vesical (g) & $0.161 \pm 0.016$ & $0.161 \pm 0.015$ & 0.001 & 0.997 \\
\hline
\end{tabular}

Values are means \pm SE. Values for a specific parameter that share different superscripts are significantly different at $\mathrm{P}<0.05$, determined by General Linear Model multivariate analysis followed by Bonferroni post hoc tests with body mass as the covariate. 
Lengh of small intestine, caecum, colon was also not influenced by aldicarb treatment (Table 1).

\subsection{White Blood Cells}

Aldicarb exposure had no significant influence on white blood cells $(\mathrm{t}=0.222, \mathrm{df}=21, \mathrm{P}=0.827$ ) (Figure 2).

\subsection{Total Antioxidant Capacity}

Aldicarb exposure suppressed total antioxidant capacity ( $\mathrm{T}$-AOC) in liver $(\mathrm{t}=6.451$, $\mathrm{df}=21, \mathrm{P}<0.001$ ) (Figure 3(a)) but not in kidneys $(\mathrm{t}=0.293, \mathrm{df}=21, \mathrm{P}=0.772$ ) (Figure 3(b)).

\subsection{Cellular Immune Response}

PHA response in the control and the aldicarb treated group did not differ after $6 \mathrm{~h}(\mathrm{t}=1.133, \mathrm{df}=21, \mathrm{P}=0.270)$, $12 \mathrm{~h}(\mathrm{t}=-0.549, \mathrm{df}=21, \mathrm{P}=0.589), 24 \mathrm{~h}(\mathrm{t}=-0.398, \mathrm{df}=21, \mathrm{P}=0.695), 48 \mathrm{~h}(\mathrm{t}=0.651, \mathrm{df}=21, \mathrm{P}=0.522)$, $72 \mathrm{~h}(\mathrm{t}=1.804, \mathrm{df}=21, \mathrm{P}=0.086)$ of PHA injection (Figure 4).

\section{Discussion}

Contrary to our expectation, cellular immunity, thymus and spleen mass and white blood cells were all not affected by aldicarb treatment in Kunming mice. However, aldicarb exposure suppressed total antioxidant capacity in liver but not in kidneys in mice.

\subsection{Immunity and Aldicarb}

Our findings that cellular immunity, thymus and spleen mass and white blood cells were not response to aldicarb exposure were consistent with other researches in which many immunological parameters including humoral,

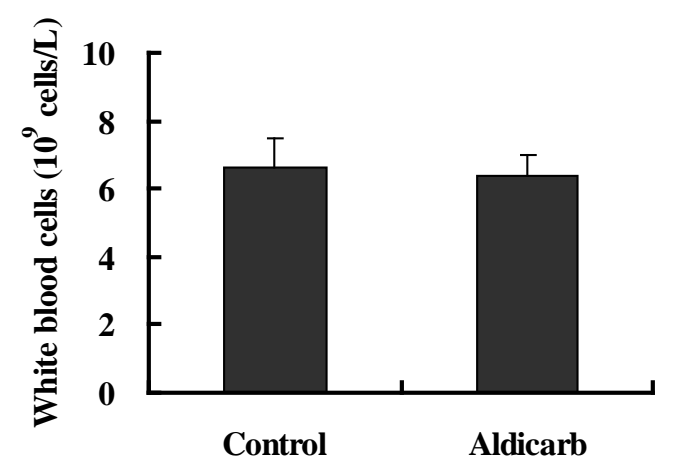

Figure 2. Effect of aldicarb treatment on white blood cells in mice. Values are means \pm SE. WBC did not differ between the control and the aldicarb treated groups.

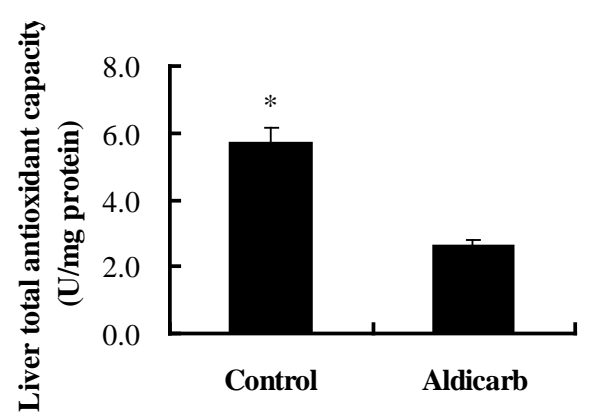

(a)

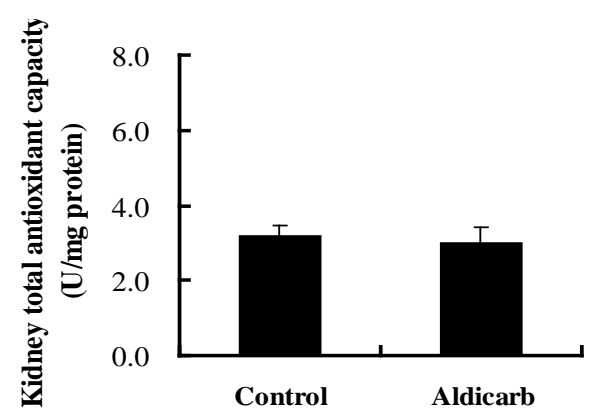

(b)

Figure 3. Effect of aldicarb treatment on total antioxidant capacity in liver (a) and kidneys (b) in mice. Values are means \pm SE. An asterisk $\left({ }^{*}\right)$ indicates statistical differences at $\mathrm{P}<0.05$. 


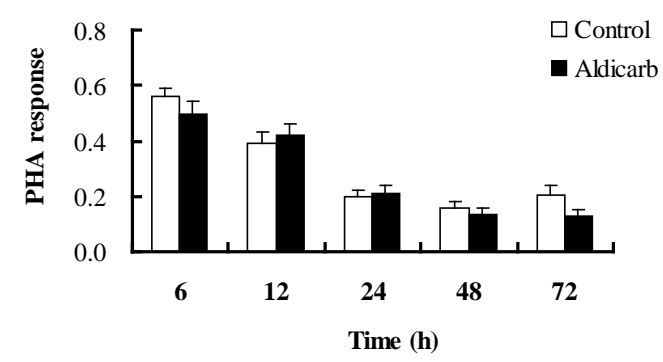

Figure 4. Effect of aldicarb treatment on PHA response in mice. Values are means \pm SE.

cellular and nonspecific immunity in mice [11]-[13]. The reason might be due to the mice used in our and other studies were adult animals. Generally, juvenile animals are often more sensitive to the toxic effects of aldicarb [23]. The absence of significant effects on any of these parameters implies that aldicarb at low exposure concentrations did not impair immune function in rodents. However, our results disagreed with other findings in which abnormalities in T-cell subsets were associated with the consumption of aldicarb-contaminated groundwater in women [8] [9]. Moreover, the stimulatory activity of macrophages was inhibited by aldicarb exposure [10]. The discrepancies in different researches might be due to the differences in subjects investigated, the treatment mode and the immune parameters measured.

\subsection{Antioxidant Capacity and Aldicarb}

In the present study, aldicarb exposure decreased total antioxidant capacity in liver in Kunming mice. This result agreed with other research, in which aldicarb exposure induced a significant decrease in antioxidant capacity such as the glutathione reductase, the glutathione peroxidase and the glutathione S-transferase activities in Chinese Hamster Ovary (CHO-K1) cells [24]. However, total antioxidant capacity in kidney was not affected by aldicarb treatment, implying that effects of aldicarb exposure on antioxidant capacity were tissues specific. In addition, aldicarb increased malondialdehyde (MDA) production indicative of lipid peroxidation in CHO-K1 cells [24]. Yarsan et al. (1999) also found that high doses of aldicarb stimulated lipid peroxidation in a mammalian test species after subacute, subchronic and chronic expositions. Lipid peroxidation in liver and kidneys were not detected in our study. Thus further researches were required to clarify whether oxidative stress such as lipid peroxidation occurred in liver and kidneys and other organs after aldicarb exposure.

\subsection{Body Composition and Aldicarb}

Body mass and all organ masses detected including heart, lungs, liver, kidneys, stomach, small intestine, caecum, colon, testes, epididymis, seminal vesicals, thymus and spleen indicated that aldicarb exposure had no significant effect on body composition. Aldicarb treatment had no significant influence on lengh of small intestine, caecum, colon and contents with stomath, small intestine, caecum, colon, implying that the digestive capacity in mice was not affected by aldicarb exposure.

\section{Conclusion}

In summary, aldicarb exposure had no significant effect on immunological parameters including cellular immune response, thymus, spleen and white blood cells, kidney total antioxidant capacity, body mass and many organ masses detected in Kunming mice. However, aldicarb exposure suppressed total antioxidant capacity in liver in mice. Taken together, aldicarb exposure exerts different impact on different biological processes.

\section{Acknowledgements}

We are grateful for the detailed comments and suggestions provided by each of the reviewers. The present study was supported by grants from the National Natural Science Foundation of China (No. 31370427), Natural Science Foundation of Shandong province (ZR2013CM019) and Undergraduate Scientific Research and Training Program of Qufu Normal University (201410446004; 2013A050). 


\section{References}

[1] Somashekar, K.M., Mahima, M.R. and Manjunath, K.C. (2015) Contamination of Water Sources in Mysore City by Pesticide Residues and Plasticizer-A Cause of Health Concern. Aquatic Procedia, 4, 1181-1188. http://dx.doi.org/10.1016/j.aqpro.2015.02.150

[2] Yarsan, E., Tanyuksel, M., Celik, S. and Aydin, A. (1999) Effects of Aldicarb and Malathion on Lipid Peroxidation. Bulletin of Environmental Contamination and Toxicology, 63, 575-581. http://dx.doi.org/10.1007/s001289901019

[3] Moser, V.C. (2014) Reference Module in Biomedical Sciences, from Encyclopedia of Toxicology. 3rd Edition, 123125.

[4] Ruiz-Suárez, N., Boada, L.D., Henríquez-Hernández, L.A., González-Moreo, F., Suárez-Pérez, A., Camacho, M., Zumbado, M., Almeida-González, M., Travieso-Aja, M.M. and Luzardo, O.P. (2015) Continued Implication of the Banned Pesticides Carbofuran and Aldicarb in the Poisoning of Domestic and Wild Animals of the Canary Islands (Spain). Science of the Total Environment, 505, 1093-1099. http://dx.doi.org/10.1016/j.scitotenv.2014.10.093

[5] Maran, E., Fernandez, M., Barbieri, P., Font, G. and Ruiz, M.J. (2009) Effects of Four Carbamate Compounds on Antioxidant Parameters. Ecotoxicology and Environmental Safety, 72, 922-930. http://dx.doi.org/10.1016/j.ecoenv.2008.01.018

[6] Han, Y.Q. (2013) Is It All “My” Mistakes? Self-Introduction of Aldicarb. Pestcides Market Information.

[7] Calder, P.C. and Kew, S. (2002) The Immune System: A Target for Functional Foods? British Journal of Nutrition, 88, S165-S176. http://dx.doi.org/10.1079/BJN2002682

[8] Fiore, M.C., Anderson, H.A., Hong, R., Golubjatnikov, R., Seiser, J.E., Nordstrom, D.L. and Belluck, D. (1986) Chronic Exposure to Aldicarb-Contaminated Groundwater and Human Immune Function. Environmental Research, 41, 633-645. http://dx.doi.org/10.1016/S0013-9351(86)80157-8

[9] Mirkin, I.R., Anderson, H.A., Hanrahan, L., Hong, R., Golubjatnikov, R. and Belluck, D. (1990) Changes in T-Lymphocyte Distribution Associated with Ingestion of Aldicarb-Contaminated Drinking Water: A Follow-Up Study. Environmental Research, 51, 35-50. http://dx.doi.org/10.1016/S0013-9351(05)80181-1

[10] Dean, T.N., Selvan, R.S., Misra, H.P., Nagarkatti, M. and Nagarkatti, P.S. (1990) Aldicarb Treatment Inhibits the Stimulatory Activity of Macrophages without Affecting the T-Cell Responses in the Syngeneic Mixed Lymphocyte Reaction. International Journal of Immunopharmacology, 12, 337-348. http://dx.doi.org/10.1016/0192-0561(90)90091-Z

[11] Thomas, P., Ratajczak, H., Demetral, D., Hagen, K. and Baron, R. (1990) Aldicarb Immunotoxicity: Functional Analysis of Cell-Mediated Immunity and Quantitation of Lymphocyte Subpopulations. Fundamental and Applied Toxicology, 15, 221-230. http://dx.doi.org/10.1016/0272-0590(90)90049-P

[12] Thomas, R.T., Ratajczak, H.V., Eisenberg, W.C., Furedi-Machacek, M., Ketels, K.V. and Barbera, P.W. (1987) Evaluation of Host Resistance and Immunity in Mice Exposed to the Carbamate Pesticide Aldicarb. Fundamental and Applied Toxicology, 9, 82-89. http://dx.doi.org/10.1016/0272-0590(87)90156-4

[13] Hajoui, O., Flipo, D., Mansour, S., Fournier, M. and Krzystyniak, K. (1992) Immunotoxicity of Subchronic versus Chronic Exposure to Aldicarb in Mice. International Journal of Immunopharmacology, 14, 1203-1211. http://dx.doi.org/10.1016/0192-0561(92)90056-Q

[14] Smits, J.E., Bortolotti, G.R. and Tella, J.L. (1999) Simplifying the Phytohaemagglutinin Skin-Testing Technique in Studies of Avian Immunocompetence. Functional Ecology, 13, 567-572. http://dx.doi.org/10.1046/j.1365-2435.1999.00338.x

[15] Bellocq, J.G., Krasnov, B.R., Khokhlova, I.S. and Pinshow, B. (2006) Temporal Dynamics of a T-Cell Mediated Immune Response in Desert Rodents. Comparative and Biochemical Physiology Part A, 145, 554-559. http://dx.doi.org/10.1016/j.cbpa.2006.08.045

[16] Savino, W. and Dardenne, M. (2000) Neuroendocrine Control of Thymus Physiology. Endocrine Review, 21, $412-443$. http://dx.doi.org/10.1210/er.21.4.412

[17] Smith, K.G. and Hunt, J.L. (2004) On the Use of Spleen Mass as a Measure of Avian Immune System Strength. Oecologia, 138, 28-31. http://dx.doi.org/10.1007/s00442-003-1409-y

[18] Finkel, T. and Holbrook, N.J. (2000) Oxidants, Oxidative Stress and the Biology of Ageing. Nature, 408, $239-247$. http://dx.doi.org/10.1038/35041687

[19] Marri, V. and Richner, H. (2015) Immune Response, Oxidative Stress and Dietary Antioxidants in Great Tit Nestlings. Comparative and Biochemical Physiology Part A, 179, 192-196. http://dx.doi.org/10.1016/j.cbpa.2014.10.013

[20] Metcalfe, N.B. and Monaghan, P. (2013) Does Reproduction Cause Oxidative Stress? An Open Question. Trends in Ecology and Evolution, 28, 347-350. http://dx.doi.org/10.1016/j.tree.2013.01.015

[21] Xu, D.L. and Wang, D.H. (2010) Fasting Suppresses T Cell-Mediated Immunity in Female Mongolian gerbils (Meriones unguiculatus). Comparative and Biochemical Physiology A, 155, 25-33. 
http://dx.doi.org/10.1016/j.cbpa.2009.09.003

[22] Yang, X.P. (2004) Laboratory Manual in Animal Physiology. 1st Edition, Higher Education Press, Beijing, 91-94.

[23] Moser, V.C. (1999) Comparison of Aldicarb and Methamidophos Neurotoxicity at Different Ages in the Rat: Behavioral and Biochemical Parameters. Toxicology and Applied Pharmacology, 157, 94-106. http://dx.doi.org/10.1006/taap.1999.8675

[24] Maran, E., Fernández-Franzón, M., Font, G. and Ruiz, M.J. (2010) Effects of Aldicarb and Propoxur on Cytotoxicity and Lipid Peroxidation in CHO-K1 Cells. Food and Chemical Toxicology, 48, 1592-1596.

http://dx.doi.org/10.1016/j.fct.2010.03.030 